Annals of Pure and Applied Mathematics

Vol. 15, No. 2, 2017, 163-171

ISSN: 2279-087X (P), 2279-0888(online)

Published on 11 December 2017

www.researchmathsci.org

DOI: http://dx.doi.org/10.22457/apam.v15n2a2

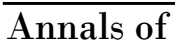 \\ Pure and Applied \\ Mathematics
}

\section{A New Method on Solving Intuitionistic Fuzzy Transportation Problem}

\author{
A.Nagoor Gani ${ }^{1}$ and S.Abbas ${ }^{2}$ \\ ${ }^{1}$ PG \& Research Department of Mathematics, Jamal Mohamed College \\ Tiruchirappalli, Tamilnadu, India. e-mail: ganijmc@yahoo.co.in \\ ${ }^{2}$ PG\& Research Department of Mathematics, Khadir Mohideen College \\ Adirampattinam, Tamilnadu, India. e-mail: abbas.kmc@gmail.com
}

Received 1 November 2017; accepted 9 December 2017

\begin{abstract}
In this paper, we find the optimum solution for an triangular intuitionistic fuzzy transportation problem using monalisha's approximation method. Using this method we could get the optimum solution directly. An illustrative numerical example was given.
\end{abstract}

Keywords: Intuitionistic Fuzzy Transportation Problem, Triangular Intuitionistic Fuzzy Number

AMS Mathematics Subject Classification (2010): 03E72, 90B06, 03F55

\section{Introduction}

Transportation Problem (TP) is based on supply and demand of commodities transported from several sources to the different destinations. The sources from which we need to transport refer the supply while the destination where commodities arrive referred the demand. It has been seen that on many occasion, the decision problem can also be formatting as TP. In general we try to minimize total transportation cost for the commodities transporting from source to destination.

A Fuzzy Transportation Problem (FTP) is a Transportation Problem (TP) in which the supply and demand are fuzzy quantities. The objective of the FTP is to determine the shipping schedule that minimizes the total fuzzy transportation cost while satisfying fuzzy supply and fuzzy demand. In [5], Nagoor Gani et al. presented a two stage cost minimizing fuzzy transportation problem in which supplies and demands are trapezoidal fuzzy numbers.

The concept of Intuitionistic Fuzzy Sets (IFSs) proposed by Atanassov[1] in 1986 is found to be highly useful to deal with vagueness. The major advantage of IFS over fuzzy set is that IFSs separate the degree of membership (belongingness) and the degree of non-membership (non-belongingness) of an element in the set. In [3], Nagoor Gani et al. Solving Intuitionistic Fuzzy Transportation Problem Using Zero Suffix Algorithm.

The remainder of this paper is organized as follows. Preliminaries of Intuitionistic Fuzzy Set's and Accuracy Function are reviewed in Section 2. In Section 3,Arithmetic Operations of Triangular Intuitionistic Fuzzy Number are explained.Intuitionistic Fuzzy 
Transportation Problem(IFTP) is explained in Section 4.In Section 5, Monalisha's Approximation Method is introduced and the steps are explained. A Numerical Example is illustrated in Section 6.

\section{Preliminaries}

\section{Definition 2.1. Intuitionistic Fuzzy Set (IFS)}

An Intuitionistic fuzzy set (IFS) $\tilde{A}^{I}$ in $\mathrm{X}$ is given by a set of ordered triples :

$$
\tilde{A}^{I}=\left\{<\mathrm{x}, \mu_{\tilde{A}^{I}}(\mathrm{x}), \nu_{\tilde{A}^{I}}(\mathrm{x})>/ \mathrm{x} \in \mathrm{X}\right\},
$$

where $\mu_{\tilde{A}^{I}}, V_{\tilde{A}^{I}}: \mathrm{X} \rightarrow[0,1]$ are functions such that $0 \leq \mu_{\tilde{A}^{I}}(\mathrm{x})+\nu_{\tilde{A}^{I}}(\mathrm{x}) \leq 1$ for all $\mathrm{x} \in$ $\mathrm{X}$. For each $\mathrm{x}$ the numbers $\mu_{\tilde{A}^{I}}(\mathrm{x})$ and $v_{\tilde{A}^{I}}(\mathrm{x})$ represent the degree of membership and degree of non-membership of the element $\mathrm{x} \in \mathrm{X}$ to $\mathrm{A} \subset \mathrm{X}$, respectively.

\section{Definition 2.2. Intuitionistic Fuzzy Number (IFN)}

An intuitionistic fuzzy subset $\tilde{A}^{I}=\left\{\left\langle\mathrm{x}, \mu_{\tilde{A}^{I}}(\mathrm{x}), \nu_{\tilde{A}^{I}}(\mathrm{x})>/ \mathrm{x} \in \mathrm{X}\right\}\right.$, of the real line $\mathrm{R}$ is called an Intuitionistic Fuzzy Number (IFN) if the following holds:

i) There exist $\mathrm{m} \in \mathrm{R}, \boldsymbol{\mu}_{\tilde{A}^{I}}(\mathrm{~m})=1$ and $\boldsymbol{V}_{\tilde{A}^{I}}(\mathrm{~m})=0$.

ii) $\mu_{\mathrm{A}}$ is a continuous mapping from $\mathrm{R}$ to the closed interval [ 0,1$]$ and $\forall \mathrm{x} \in \mathrm{R}$, the relation $0 \leq \mu_{\tilde{A}^{I}}(\mathrm{x})+\nu_{\tilde{A}^{I}}(\mathrm{x}) \leq 1$ holds.

The membership and non-membership function of $\tilde{A}^{I}$ is of the following form:

$$
\mu_{\tilde{A}^{I}}(\mathrm{x})= \begin{cases}0 & \text { for }-\propto<\mathrm{x} \leq \mathrm{m}-\alpha \\ \mathrm{f}_{1}(\mathrm{x}) & \text { for } \mathrm{x} \in[\mathrm{m}-\alpha, \mathrm{m}] \\ 1 & \text { for } \mathrm{x}=\mathrm{m} \\ \mathrm{h}_{1}(\mathrm{x}) & \text { for } \mathrm{x} \in[\mathrm{m}, \mathrm{m}+\beta] \\ 0 & \text { for } \mathrm{m}+\beta \leq \mathrm{x}<\propto\end{cases}
$$

where $f_{1}(x)$ and $h_{1}(x)$ are strictly increasing and decreasing function in $[\mathrm{m}-\alpha, \mathrm{m}]$ and $[\mathrm{m}, \mathrm{m}+\beta]$ respectively.

$$
v_{\tilde{A}^{I}}(\mathrm{x})= \begin{cases}1 & \text { for }-\propto<\mathrm{x} \leq \mathrm{m}-\alpha^{\prime} \\ \mathrm{f}_{2}(\mathrm{x}) & \text { for } \mathrm{x} \in\left[\mathrm{m}-\alpha^{\prime}, \mathrm{m}\right] ; 0 \leq \mathrm{f}_{1}(\mathrm{x})+\mathrm{f}_{2}(\mathrm{x}) \leq 1 \\ 0 & \text { for } \mathrm{x}=\mathrm{m} \\ \mathrm{h}_{2}(\mathrm{x}) & \text { for } \mathrm{x} \in\left[\mathrm{m}, \mathrm{m}+\beta^{\prime}\right] ; 0 \leq \mathrm{h}_{1}(\mathrm{x})+\mathrm{h}_{2}(\mathrm{x}) \leq 1 \\ 1 & \text { for } \mathrm{m}+\beta^{\prime} \leq \mathrm{x} \leq \alpha\end{cases}
$$


Solving Triangular Intuitionistic Fuzzy Transportation Problem

Here $\mathrm{m}$ is the mean value of $\tilde{A}^{I} . \alpha$ and $\beta$ are called left and right spreads of membership function $\mu_{\widetilde{A}^{I}}$ (x) respectively. $\alpha^{\prime}$ and $\beta^{\prime}$ represents left and right spreads of non membership function $V_{\tilde{A}^{I}}$ (x ) respectively. Symbolically, the intuitionistic fuzzy number is represented as $\tilde{A}_{\mathrm{IFN}}^{I}=\left(\mathrm{m} ; \alpha, \beta ; \alpha^{\prime}, \beta^{\prime}\right)$.

\section{Definition 2.3. Triangular Intuitionistic Fuzzy Number (TIFN)}

A Triangular Intuitionistic Fuzzy Number $\tilde{A}^{I}$ is an intuitionistic fuzzy set in $\mathrm{R}$ with the following membership function $\mu_{\tilde{A}^{I}}(\mathrm{x})$ and non membership function $v_{\tilde{A}^{I}}(\mathrm{x})$ :

$$
\begin{aligned}
& \mu_{\tilde{A}^{I}}(x)= \begin{cases}\frac{x-a_{1}}{a_{2}-a_{1}} \text { for } \mathrm{a}_{1} \leq \mathrm{x} \leq \mathrm{a}_{2} \\
\frac{a_{3}-x}{a_{3}-a_{2}} & \text { for } \mathrm{a}_{2} \leq \mathrm{x} \leq \mathrm{a}_{3} \\
0 & \text { Otherwise }\end{cases} \\
& V_{\tilde{A}^{I}}(x)= \begin{cases}\frac{a_{2}-x}{a_{2}-a_{1}^{\prime}} \text { for } \mathrm{a}_{1}^{\prime} \leq \mathrm{x} \leq \mathrm{a}_{2} \\
\frac{x-a_{2}}{a_{3}^{\prime}-a_{2}} & \text { for } \mathrm{a}_{2} \leq \mathrm{x} \leq \mathrm{a}_{3}^{\prime} \\
1 & \text { Otherwise }\end{cases}
\end{aligned}
$$

where $\mathrm{a}_{1}{ }^{\prime} \leq \mathrm{a}_{1} \leq \mathrm{a}_{2} \leq \mathrm{a}_{3} \leq \mathrm{a}_{3}{ }^{\prime}$ and $\mu_{\widetilde{A}^{I}}(\mathrm{x})+\nu_{\tilde{A}^{I}}(\mathrm{x}) \leq 1$ or $\quad \mu_{\tilde{A}^{I}}(\mathrm{x})=\nu_{\tilde{A}^{I}}(\mathrm{x}) \forall \mathrm{x} \in \mathrm{R}$. This TIFN is denoted by $\tilde{A}^{I}{ }_{\text {TIFN }}=\left\{\left(\mathrm{a}_{1}, \mathrm{a}_{2}, \mathrm{a}_{3}\right) ;\left(\mathrm{a}_{1}{ }^{\prime}, \mathrm{a}_{2}, \mathrm{a}_{3}{ }^{\prime}\right)\right\}$.

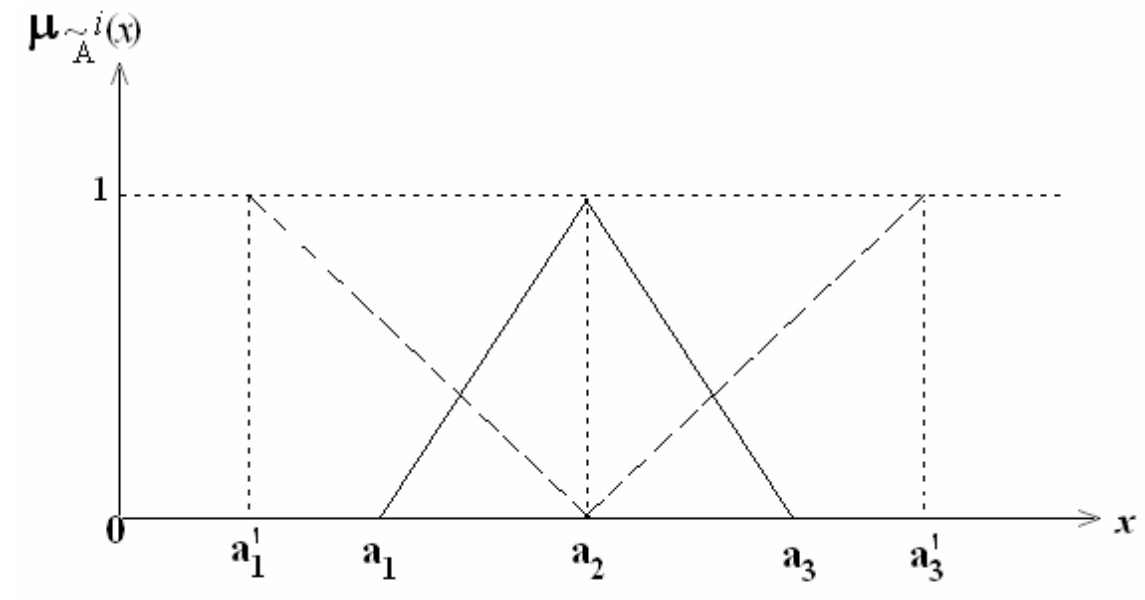

Membership and non-membership functions of TIFN

Figure 1: 


\section{Definition 2.4. Accuracy Function}

We define

$$
H\left(\tilde{A}^{I}\right)=\frac{\left(a_{1}+2 a_{2}+a_{3}\right)+\left(a_{1}^{\prime}+2 a_{2}+a_{3}^{\prime}\right)}{8},
$$

an accuracy function of $\tilde{A}^{I}$, to defuzzify the given number.

\section{Arithmetic operations of triangular intuitionistic fuzzy number}

Let $\tilde{a}^{I}=\left\{\left(\mathrm{a}_{1}, \mathrm{a}_{2}, \mathrm{a}_{3}\right) ;\left(\mathrm{a}_{1}{ }^{\prime}, \mathrm{a}_{2}, \mathrm{a}_{3}{ }^{\prime}\right)\right\} \quad$ and $\tilde{b}^{I}=\left\{\left(\mathrm{b}_{1}, \mathrm{~b}_{2}, \mathrm{~b}_{3}\right) ;\left(\mathrm{b}_{1}{ }^{\prime}, \mathrm{b}_{2}, \mathrm{~b}_{3}{ }^{\prime}\right)\right\}$ two triangular Intuitionistic fuzzy number then the arithmetic operations on $\tilde{a}^{I}$ and $\tilde{b}^{I}$ as follows :

Addition $\quad: \tilde{a}^{I} \oplus \tilde{b}^{I}=\left(\mathrm{a}_{1}+\mathrm{b}_{1}, \mathrm{a}_{2}+\mathrm{b}_{2}, \mathrm{a}_{3}+\mathrm{b}_{3}\right)\left(\mathrm{a}_{1}{ }^{\prime}+\mathrm{b}_{1}{ }^{\prime}, \mathrm{a}_{2}+\mathrm{b}_{2}, \mathrm{a}_{3}{ }^{\prime}+\mathrm{b}_{3}{ }^{\prime}\right)$

Subtraction : $\tilde{a}^{I} \Theta \tilde{b}^{I}=\left(\mathrm{a}_{1}-\mathrm{b}_{3}, \mathrm{a}_{2}-\mathrm{b}_{2}, \mathrm{a}_{3}-\mathrm{b}_{1}\right)\left(\mathrm{a}_{1}{ }^{\prime}-\mathrm{b}_{3}{ }^{\prime}, \mathrm{a}_{2}-\mathrm{b}_{2}, \mathrm{a}_{3}{ }^{\prime}-\mathrm{b}_{1}{ }^{\prime}\right)$

Multiplication: $\tilde{a}^{I} \otimes \tilde{b}^{I}=\left(\mathrm{a}_{1} \mathrm{~b}_{1}, \mathrm{a}_{2} \mathrm{~b}_{2}, \mathrm{a}_{3} \mathrm{~b}_{3}\right)\left(\mathrm{a}_{1}{ }^{\prime} \mathrm{b}_{1}{ }^{\prime}, \mathrm{a}_{2} \mathrm{~b}_{2}, \mathrm{a}_{3}{ }^{\prime} \mathrm{b}_{3}{ }^{\prime}\right)$

Scalar Multiplication : (i) If $\mathrm{k}>0$ then $\mathrm{k} \tilde{a}^{I}=\left(\mathrm{ka}_{1}, \mathrm{ka}_{2}, \mathrm{ka}_{3}\right)\left(\mathrm{ka}_{1}{ }^{\prime}, \mathrm{ka}_{2}, \mathrm{ka}_{3}{ }^{\prime}\right)$

(ii) If $\mathrm{k}<0$ then $\mathrm{k} \tilde{a}^{I}=\left(\mathrm{ka}_{3}, \mathrm{ka}_{2}, \mathrm{ka}_{1}\right)\left(\mathrm{ka}_{3}{ }^{\prime}, \mathrm{ka}_{2}, \mathrm{ka}_{1}{ }^{\prime}\right)$

\section{Intuitionistic fuzzy transportation problem (IFTP)}

Consider a transportation with $m$ Intuitionistic Fuzzy (IF) origins and $\mathrm{n}$ IF destination. Let $C_{i j}(i=1,2, \ldots, m, j=1,2, \ldots, n)$ be the cost of transporting one unit of the product form $i^{\text {th }}$ origin to $\mathrm{j}^{\text {th }}$ destination .Let $\tilde{a}^{I}{ }_{\mathrm{i}}(\mathrm{i}=1,2, \ldots, \mathrm{m})$ be the quantity of commodity available at IF origin $i$. Let $\tilde{b}^{I}{ }_{\mathrm{j}}(\mathrm{j}=1,2, \ldots, \mathrm{n})$ be the quantity of commodity needed of IF destination $j$. Let $X_{i j}(i=1,2, \ldots, m, j=1,2, \ldots, n)$ is quantity transported from $i^{\text {th }}$ IF origin to $\mathrm{j}^{\text {th }}$ destination.

Mathematical Model of Intuitionistic Fuzzy Transportation Problem is Minimize $\tilde{Z}^{I}=\sum_{i=1}^{m} \sum_{j=1}^{n} \tilde{x}_{i j}^{I} \tilde{c}_{i j}^{I}$

$$
\begin{aligned}
& \sum_{i=1}^{n} \tilde{x}_{i j}^{I}=\tilde{a}_{i}^{I}, \quad i=1,2, \ldots, m \\
& \sum_{i=1}^{n} \tilde{x}_{i j}^{I}=\tilde{b}_{j}^{I}, \quad j=1,2, \ldots, n \\
& \tilde{x}_{i j}^{I} \geq 0 \text { for all } \mathrm{i} \text { and } \mathrm{j}
\end{aligned}
$$

The above IFTP can be stated in the below tabular form. 
Solving Triangular Intuitionistic Fuzzy Transportation Problem

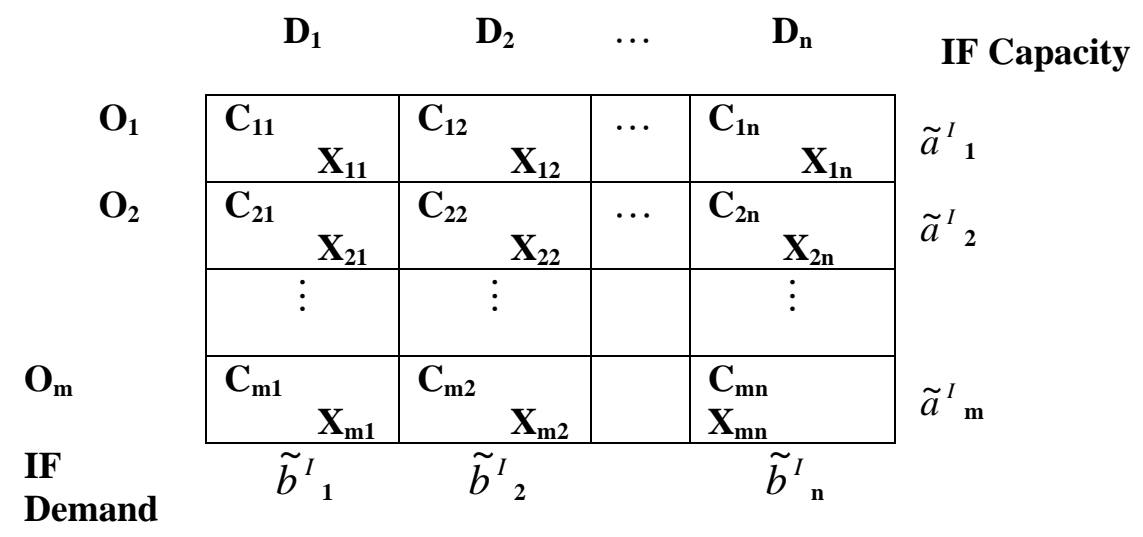

\section{Monalisha's approximation method (MAM's) model}

Step 1: Determine the cost table from the given problem.

(i) Examine whether total demand equals total demand. If yes, go to step 2.

(ii) If not, introduce a dummy row/column having all its cost elements as zero and supply/ demand as the (+ve) difference of supply and demand.

Step 2: Locate the smallest element in each row of the given cost matrix and then subtract the same from each element of that row.

Step 3: In the reduced matrix obtained in step 2, locate the smallest element of each column and then subtract the same from each element of that column.

Step 4: For each row of the transportation table identify the smallest and the next - to smallest costs. Determine the difference between them for each row. Display them alongside the transportation table by enclosing them in parenthesis against the respective rows. Similarly compute the differences for each column.

Step 5: Identify the row or column with the largest difference among all the rows and columns. If a tie occurs, use any arbitrary tiebreaking choice. Let the greatest difference correspond to $\mathrm{i}^{\text {th }}$ row and let 0 be in the $\mathrm{i}^{\text {th }}$ row. Allocate the maximum feasible amount $\mathrm{x}_{\mathrm{ij}}=\min \left(\mathrm{a}_{\mathrm{i}}, \mathrm{b}_{\mathrm{j}}\right)$ in the $(\mathrm{i}, \mathrm{j})^{\text {th }}$ cell and cross off either the $\mathrm{i}^{\text {th }}$ row or the $\mathrm{j}^{\text {th }}$ column in the usual manner.

Step 6: Recompute the column and row differences for the reduced transportation table and go to step 5. Repeat the procedure until all the rim requirements (the various origin capacities and destination requirements are listed in the right most outer column and the bottom outer row respectively) are satisfied.

\section{Numerical example}

Consider the following $3 \times 3$ Intuitionistic Fuzzy Transportation Problem whose quantities are Triangular Intuitionistic Fuzzy Numbers. 
A.Nagoor Gani and S.Abbas

\begin{tabular}{|c|c|c|c|c|}
\hline & $\mathrm{D}_{1}$ & $\mathrm{D}_{2}$ & $\mathrm{D}_{3}$ & \\
\hline $\mathrm{O}_{1}$ & $(14,16,18 ; 13,16,19)$ & $(19,20,21 ; 18,20,22)$ & $(10,12,14 ; 9,12,15)$ & $(18,20,22 ; 16,20,23)$ \\
\hline $\mathrm{O}_{2}$ & $(13,14,15 ; 12,14,16)$ & $(6,8,10 ; 5,8,11)$ & $(16,18,20 ; 15,18,21)$ & $(15,16,18 ; 14,16,19)$ \\
\hline $\mathrm{O}_{3}$ & $(24,26,28 ; 23,26,29)$ & $(22,24,26 ; 21,24,27)$ & $(13,16,19 ; 12,16,20)$ & $(7,9,12 ; 5,9,13)$ \\
\hline & $(16,18,21 ; 14,18,22)$ & $(11,12,14 ; 9,12,15)$ & $(13,15,17 ; 12,15,18)$ & \\
\hline
\end{tabular}

\section{Solution:}

By Defuzzifying the quantities we get, $\mathrm{a}_{11}=16, \mathrm{a}_{12}=20, \mathrm{a}_{13}=12, \mathrm{a}_{21}=14, \mathrm{a}_{22}=8, \mathrm{a}_{23}=18$, $\mathrm{a}_{31}=26, \mathrm{a}_{32}=24$ and $\mathrm{a}_{33}=16$. Hence

\begin{tabular}{|c|c|c|c|c|}
\hline & $\mathrm{D}_{1}$ & $\mathrm{D}_{2}$ & $\mathrm{D}_{3}$ & \\
\hline $\mathrm{O}_{1}$ & 16 & 20 & 12 & $(18,20,22 ; 16,20,23)$ \\
\hline $\mathrm{O}_{2}$ & 14 & 8 & 18 & $(15,16,18 ; 14,16,19)$ \\
\hline $\mathrm{O}_{3}$ & 26 & 24 & 16 & $(7,9,12 ; 5,9,13)$ \\
\hline & $(16,18,21 ; 14,18,22)$ & $(11,12,14 ; 9,12,15)$ & $(13,15,17 ; 12,15,18)$ & \\
\hline
\end{tabular}

Step 1:

Determine the cost table from the given problem.

\begin{tabular}{|c|c|c|c|c|}
\hline & $\mathrm{D}_{1}$ & $\mathrm{D}_{2}$ & $\mathrm{D}_{3}$ & \\
\hline $\mathrm{O}_{1}$ & 16 & 20 & 12 & $(18,20,22 ; 16,20,23)$ \\
\hline $\mathrm{O}_{2}$ & 14 & 8 & 18 & $(15,16,18 ; 14,16,19)$ \\
\hline $\mathrm{O}_{3}$ & 26 & 24 & 16 & $(7,9,12 ; 5,9,13)$ \\
\hline & $(16,18,21 ; 14,18,22)$ & $(11,12,14 ; 9,12,15)$ & $(13,15,17 ; 12,15,18)$ & $(40,45,52 ; 35,45,55)$ \\
\hline
\end{tabular}

Here total demand equals total supply, go to step 2 .

\section{Step 2:}

Locating the smallest element in each row of the given cost matrix and then subtracting the same from each element of that row.

\begin{tabular}{|c|c|c|c|c|}
\hline & $\mathrm{D}_{1}$ & $\mathrm{D}_{2}$ & $\mathrm{D}_{3}$ & \\
\hline $\mathrm{O}_{1}$ & 4 & 8 & 0 & $(18,20,22 ; 16,20,23)$ \\
\hline $\mathrm{O}_{2}$ & 6 & 0 & 10 & $(15,16,18 ; 14,16,19)$ \\
\hline $\mathrm{O}_{3}$ & 10 & 8 & 0 & $(7,9,12 ; 5,9,13)$ \\
\hline & $(16,18,21 ; 14,18,22)$ & $(11,12,14 ; 9,12,15)$ & $(13,15,17 ; 12,15,18)$ & $(40,45,52 ; 35,45,55)$ \\
\hline
\end{tabular}

\section{Step 3:}

In the reduced matrix obtained in step 2, locating the smallest element of each column and then subtracting the same from each element of that column. 
Solving Triangular Intuitionistic Fuzzy Transportation Problem

\begin{tabular}{|c|c|c|c|c|}
\hline & $\mathrm{D}_{1}$ & $\mathrm{D}_{2}$ & $\mathrm{D}_{3}$ & \\
\hline $\mathrm{O}_{1}$ & 0 & 8 & 0 & $(18,20,22 ; 16,20,23)$ \\
\hline $\mathrm{O}_{2}$ & 2 & 0 & 10 & $(15,16,18 ; 14,16,19)$ \\
\hline $\mathrm{O}_{3}$ & 6 & 8 & 0 & $(7,9,12 ; 5,9,13)$ \\
\hline & $(16,18,21 ; 14,18,22)$ & $(11,12,14 ; 9,12,15)$ & $(13,15,17 ; 12,15,18)$ & $(40,45,52 ; 35,45,55)$ \\
\hline
\end{tabular}

Step 4:

For each row of the transportation table identifying the smallest and the next - to smallest costs. Determining the difference between them for each row in the transportation table. Displaying them alongside the transportation table by enclosing them in parenthesis against the respective rows of the transportation table. Similarly computing the differences for each column of the transportation table.

\begin{tabular}{|c|c|c|c|c|c|}
\hline & $\mathrm{D}_{1}$ & $\mathrm{D}_{2}$ & $\mathrm{D}_{3}$ & & Penalty \\
\hline $\mathrm{O}_{1}$ & 0 & 8 & 0 & $(18,20,22 ; 16,20,23)$ & $(0)$ \\
\hline $\mathrm{O}_{2}$ & 2 & 0 & 10 & $(15,16,18 ; 14,16,19)$ & $(2)$ \\
\hline $\mathrm{O}_{3}$ & 6 & 8 & 0 & $(7,9,12 ; 5,9,13)$ & $(6)$ \\
\hline & $(16,18,21 ; 14,18,22)$ & $(11,12,14 ; 9,12,15)$ & $(13,15,17 ; 12,15,18)$ & & \multicolumn{1}{c}{} \\
\cline { 1 - 5 } & $(2)$ & $(8)$ & $(0)$ & \multicolumn{2}{c}{} \\
\cline { 2 - 5 }
\end{tabular}

Step 5:

Identifying the row or column with the largest difference among all the rows and columns. If a tie occurs, use any arbitrary tiebreaking choice. Let the greatest difference correspond to $\mathrm{i}^{\text {th }}$ row and let 0 be in the $\mathrm{i}^{\text {th }}$ row. Allocating the maximum feasible amount $\mathrm{x}_{\mathrm{ij}}=\min \left(\mathrm{a}_{\mathrm{i}}, \mathrm{b}_{\mathrm{j}}\right)$ in the $(\mathrm{i}, \mathrm{j})^{\text {th }}$ cell and cross off either the $\mathrm{i}^{\text {th }}$ row or the $\mathrm{j}^{\text {th }}$ column in the usual manner.

\begin{tabular}{|c|c|c|c|c|c|}
\hline & $\mathrm{D}_{1}$ & $\mathrm{D}_{2}$ & $\mathrm{D}_{3}$ & & Penalty \\
\hline $\mathrm{O}_{1}$ & 0 & 8 & 0 & $(18,20,22 ; 16,20,23)$ & (0) \\
\hline $\mathrm{O}_{2}$ & 2 & $\begin{array}{c}0 \\
(11,12,14 ; 9,12,15) \\
\end{array}$ & 10 & $(15,16,18 ; 14,16,19)$ & (2) \\
\hline $\mathrm{O}_{3}$ & 6 & 8 & 0 & $(7,9,12 ; 5,9,13)$ & (6) \\
\hline & $(16,18,21 ; 14,18,22)$ & $(11,12,14 ; 9,12,15)$ & $(13,15,17 ; 12,15,18)$ & & \\
\hline & (2) & (8) & (0) & & \\
\hline
\end{tabular}

\section{Step 6:}

Recomputing the column and row differences for the reduced transportation table and go to step 5. Repeating the procedure until all the rim requirements (the various origin 
A.Nagoor Gani and S.Abbas

capacities and destination requirements are listed in the right most outer column and the bottom outer row respectively) are satisfied.

The Optimal Solution is

\begin{tabular}{|c|c|c|c|c|}
\hline & $\mathrm{D}_{1}$ & $\mathrm{D}_{2}$ & $\mathrm{D}_{3}$ & \\
\hline $\mathrm{O}_{1}$ & $\begin{array}{c}(14,16,18 ; 13,16,19) \\
(9,14,20 ; 4,14,23)\end{array}$ & $(19,20,21 ; 18,20,22)$ & $\begin{array}{c}(10,12,14 ; 9,12,15) \\
(1,6,10 ;-1,6,13)\end{array}$ & $(18,20,22 ; 16,20,23)$ \\
\hline $\mathrm{O}_{2}$ & $\begin{array}{c}(13,14,15 ; 12,14,16) \\
(1,4,7 ;-1,4,10)\end{array}$ & $\begin{array}{c}(6,8,10 ; 5,8,11) \\
(11,12,14 ; 9,12,15)\end{array}$ & $\begin{array}{c}(16,18,20 ; 15,18,21) \\
(15,16,18 ; 14,16,19)\end{array}$ & $(7,9,12 ; 6,9,13)$ \\
\hline $\mathrm{O}_{3}$ & $(24,26,28 ; 23,26,29)$ & $(22,24,26 ; 21,24,27)$ & $\begin{array}{c}(13,16,19 ; 12,16,20) \\
(7,9,12 ; 5,9,13)\end{array}$ & \\
\hline & $(16,18,21 ; 14,18,22)$ & $(11,12,14 ; 9,12,15)$ & $(13,15,17 ; 12,15,18)$ & \\
\hline
\end{tabular}

Thus the optimal allocation is: $X_{11}=(9,14,20 ; 4,14,23), X_{13}=(1,6,10 ;-1,6,13)$,

$\mathrm{X}_{21}=(1,4,7 ;-1,4,10), \mathrm{X}_{22}=(11,12,14 ; 9,12,15)$,

$\mathrm{X}_{33}=(7,9,12 ; 5,9,13)$.

Total Minimum Cost $=(14,16,18 ; 13,16,19)(9,14,20 ; 4,14,23)+$

$$
\begin{array}{lll}
(10,12,14 ; 9,12,15) \quad(1,6,10 ;-1,6,13) & + \\
(13,14,15 ; 12,14,16) \quad(1,4,7 ;-1,4,10) & + \\
(6,8,10 ; 5,8,11) \quad(11,12,14 ; 9,12,15) & + \\
(13,16,19 ; 12,16,20) & (7,9,12 ; 5,9,13)
\end{array}
$$

Total Minimum Cost $=(306,592,937 ; 156,592,1217)$.

\section{Conclusion}

The main contribution of this paper is to deriving the optimal solution of a triangular intuitionistic fuzzy transportation problem using Monalisha's approximation method with fewer steps in comparison to other methods. Using this method we could get the optimum solution directly. This method is very helpful for the decision makers, since the methodology is very simple and takes less number of iterations.

\section{REFERENCES}

1. K.T.Atanassov, Intitionistic fuzzy sets, Fuzzy Sets and Systems, 20(1) (1986) 87-96.

2. G.S.Mahapatra and T.K. Roy, Reliability evaluation using triangular intuitionistic fuzzy numbers arithmetic operations, World Academy of Science, Engineering and Technology, 50 (2009) 574-581.

3. A. Nagoor Gani and S. Abbas, Solving intuitionistic fuzzy transportation problem using zero suffix algorithm, International J. of Math. Sci. \& Engg. Appl., 6(III) (2012) 73-82.

4. A. NagoorGani and S.Abbas, Revised distribution method for intuitionistic fuzzy transportation problem, Intern. J. Fuzzy Mathematical Archive, 4(2) (2014) 96-103.

5. A. Nagoor Gani and K.Abdul Razak, Two stage fuzzy transportation problem, Journal of Physical Sciences, 10 (2006) 63-69. 
Solving Triangular Intuitionistic Fuzzy Transportation Problem

6. M.Pattnaik, Transportation problem by Monalisha's approximation method for optimal solution (MAMOS), Log Forum, 11 (3) (2015) 267-273.

7. L.A.Zadeh, Fuzzy sets, Information and Computation, 8 (1965) 338-353. 